\begin{tabular}{|c|c|}
\hline \multirow{3}{*}{ 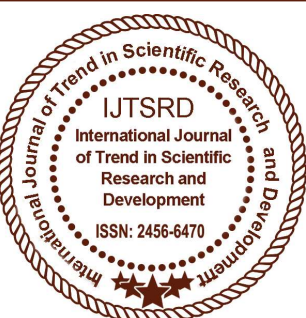 } & $\begin{array}{l}\text { International Journal of Trend in Scientific } \\
\text { Research and Development (IJTSRD) }\end{array}$ \\
\hline & Access Journal \\
\hline & ISSN No: 2456 - 6470 | www.ijtsrd.com | Volume - 2 | Issue -3 \\
\hline
\end{tabular}

\title{
Maritime Boundary Protection System Using Floating Station
}

\author{
Reshma. $\mathbf{R}^{1}$, Roslin Priyadharshini. $G^{2}$, Vishnupriya. $P^{3}$, Kapila Vani. R. $K^{4}$ \\ ${ }^{1,2,3}$ Student, ${ }^{4}$ Assistant Professor \\ CSE, Prince Shri Venkateshwara Padmavathy Engineering College, Anna University Chennai, India
}

\begin{abstract}
The Island like Sri Lanka, peninsula like India and the coastal countries are separated by their maritime borders. The people livelihood in coastal area of those countries purely depends on fishing occupation in the sea. The sea border between two countries is not easily identifiable, which is the main reason for this cross border cruelty. The main objective of this system is to help the fishermen to navigate inside our maritime country border. For this we are constructing a Floating Station uses Hybrid power which is placed in the countries border. If a fisherman navigates beyond the country's border, an alarm is generated indicating that the fisherman is nearing the border. Along with this we are using RSSI for identification of boat. Additionally a message transmitter is interfaced with this device to send a message in the encoded form to base station indicating that a vessel has crossed the border using IoT. Thus guards can assist and provide additional help to those fishermen if needed.
\end{abstract}

Keywords: Floating Station, Hybrid power, Reduced Signal Strength Indicator (RSSI), Internet of Things, Unique Identification Code (UIC)

\section{INTRODUCTION}

India and Sri Lanka share a maritime border of more than $400 \mathrm{~km}$ running along four different areas-the Bay of Bengal in the north, the Palk bay and the Gulf of Mannar in the centre and the Indian Ocean in the south. Both the countries are separated by the International Maritime Boundary line (IMBL) the minimum and the maximum distances between the two coasts area around $16 \mathrm{~km}$ and $45 \mathrm{~km}$, respectively. Both India and Sri Lanka have been fishing into the Palk Bay for centuries Often,

fishermen from both sides cross over to other side for bottom trawling fishing expeditions and that result in arrests and, on many occasions, shootings. These are the main causes which made us to construct the Floating Station at the maritime border. This floating Station is placed one per kilometer in the maritime Boundary between two countries. The figure 1.1 shows the maritime border between India and Sri Lanka.

The System we proposed not only prevents the fishermen from crossing the International Maritime Boundary Line but also enables the fisherman to report to the coastal guard on spotting the intruder. This increases the overall security to fisherman and also to our country. It also reduces the necessity for periodic patrolling of sea by the coast guard.

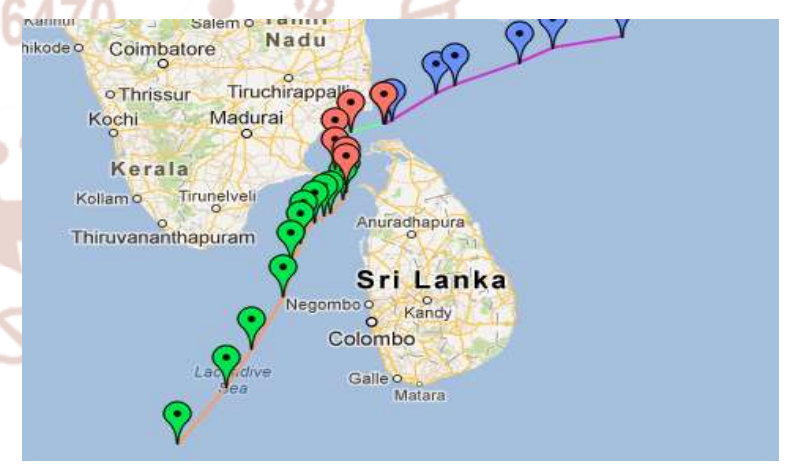

Figure 1: Maritime Boundary

\section{EXISTING SYSTEM}

At present, there are few existing system which helps to identify the current position of the boat using GPS system and view them on the electronic map. None of the present GPS system satisfies the requirements for the safety of civilian navigation in the sea as the maritime boundary of a country cannot be marked. 
Since GPS is not bi-directional we can't able to identify the movement of the boat.

\section{LITERATURE SURVEY}

\section{A Novel Approach of Geo fencing And Geo tagging System Based Sea Border identification using Embedded System}

The main theme of this paper is to save the lives of poor fishermen who is severely punishing by the other country coastal guards. This is achieved with the help of GPS and embedded system. GPS(Global Positioning System) is increasingly being used for a wide range of applications. It provides reliable positioning, navigation, and timing services to worldwide users on a continuous basis in all weather, day and night, anywhere on or near the earth. This paper deals on the versatility and the usefulness of a GPS device in the sea. The main objective of the paper is to help the fishermen not to navigate beyond other country's border. If a fisherman navigates beyond the country's border, an alarm is generated indicating that the fisherman has crossed the border. Additionally, a GSM transmitter interface will send a message to base station located on the sea shore indicating that a boat has crossed the border.

\section{ADVANTAGES}

- Guards in the shore can assist and provide additional help to those fishermen if needed.

- This device has been created to help them not to move beyond the border

- Reasonably low cost.

\section{DISADVANTAGES:}

- GPS is not bi-directional we can't able to identify the movement of the boat .

\section{PROPOSED SYSTEM}

The proposed system is used to detect the maritime boundary of the country where the longtime dispute between Sri Lanka and India all exists. It is a low cost maritime border crossing alert system mainly focused the small scale fisherman who lives just near to the poverty line. This system is a standalone device with a solar panel and a flat micro turbine (tidal energy). The proposed system makes use of UIC (unique identification code). RSSI (Reduced Signal Strength Indicator) is present and hence identification becomes easier .It also uses Battery Energy Storage System (BESS) for effective storage of energy. The RSSI calculates the distance between the boat and border.

\section{HARDWARE CONFIGURATION}

The Fig 11.1 Shows the overall setup of our system which has a Photovoltaic cell for generation of solar energy and Turbine for generation of Tidal energy. These energy are fed up into Hybrid power System. And the output of this will be given to the Embedded System. It will convert Analog to Digital, Digital to RS-232 and RS-232 to USB, via USB the message is transferred to the Floating Station.The transmitter will send the emergency messages and it will be received by the Receiver which is fixed in the Floating System placed in the maritime country Border. The

Floating Station is placed one per $25 \mathrm{~km}$ in the sea border. In order to make Floating Station not to move along the tides a Nitrogen ball weigh $10 \mathrm{~kg}$ will be placed in the $25 \mathrm{~km}$ depth of the sea from the Floating Station. This nitrogen ball will balances the Floating Station and not moves along with the tides.

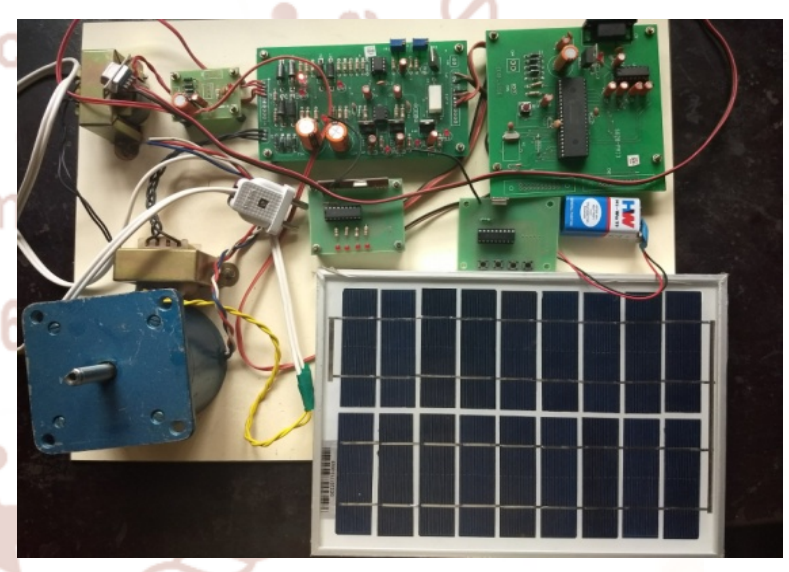

Fig 4.1. Hardware Setup of the Floating Station, Transmitter, Receiver. Hybrid Power Source, Embedded System.

\section{HARDWARE DESCRIPTION}

This System uses the Hybrid module for power generation by solar and Tidal sources. Both energies are collected by Solar Photovoltaic cell panel and Turbine respectively. To isolate these energies we use Polarity Controller. This is connected to the PIC controller. This will display the amount of power generated from the solar and Tidal turbine. The Receiver is connected to the PIC controller. The transmitter is placed in the boat. It has a transmitter module and transmitting antenna .In the Transmitter 
Module it contain 4 switches to intimate any of the issues that have happened and using antenna the message is transmitted. The receiver receives the signal from transmitting antenna, decodes it and provides to the PIC controller (Embedded Controller).The output of embedded Controller will be fed to a RS232 connector chip, RS232 output will be connected to a computer and we can view them. The figure 2. Shows the overall System architecture.

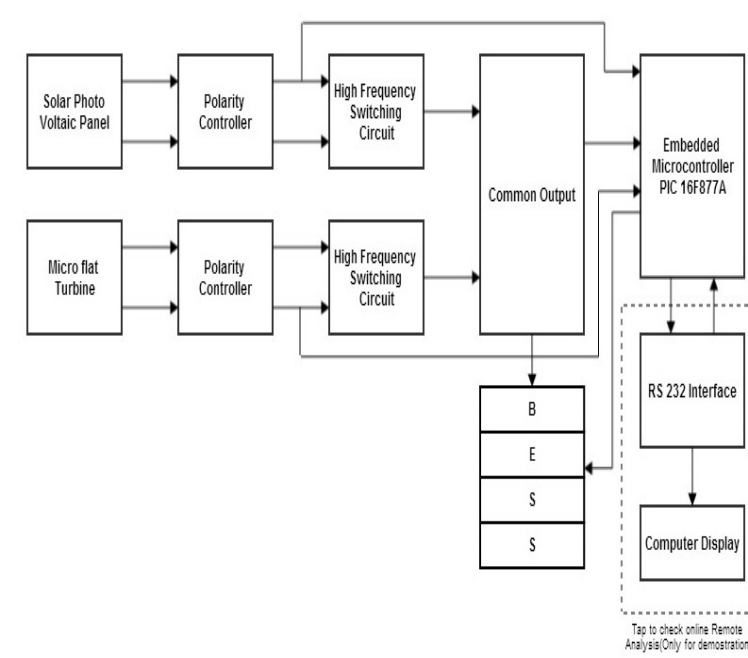

Figure 2. System Architecture

\section{GENERATION OF POWER}

The Solar energy is the oldest renewable energy resource of India. It is the fastest growing type of energy that is increasing $50 \%$ every year. It is the photovoltaic cell which directly converts sunlight into electricity. Solar cell is a $\mathrm{p}-\mathrm{n}$ junction diode of large area $\left(1-100 \mathrm{~cm}^{2}\right)$, which converts energy of incident photons into the electrical energy. A typical construction of a $p-n$ junction solar cell, which consists of a shallow $p-n$ junction formed on the surface of the substrate, front ohmic contact grids and a back ohmic contact and an anti reflection coating on the front surface. Solar energy uses the energy from the sun to react with chemical materials to produce positive and negative charges. It is in the form of Direct current and fed into the Hybrid power Source.

Tidal energy is produced by the surge of ocean waters during the rise and fall of tides. Tidal energy is a renewable source of energy. The amount of power produced so far has been small. Turbines are placed in tidal streams. A tidal stream is a fast-flowing body of water created by tides. A turbine is a machine that takes energy from a flow of fluid. They produce a stream of electricity. Since water is more denser than air, Tidal energy is powerful.

Since the Tidal energy is in the form of Alternating Current it is provided as input to the Step Down transformer to Step down $230 \mathrm{~V}$ into $70 \mathrm{~V}$. AC is applied to primary winding of the power transformer it can either be stepped down depending upon the value of DC needed. Apart from stepping down voltages it gives isolation between the power source and power supply circuitries. It is then fed into Rectifier.

After converting both the energies as Direct current it is given as input to the Hybrid Energy Source.

\section{HYBRID POWER SOURCE}

The Direct current of Solar energy and Tidal energy is fed to Hybrid power source. In order to make turbine as the generator and not as the motor we polarize the energy using polarity controller

A diode is a specialized electronic component with two electrodes called the anode and the cathode. Most diodes are made with semiconductor materials such as silicon, germanium or selenium. Diodes can be used as rectifiers, signal limiters, voltage regulators, switches, signal modulators and oscillators. The fundamental property of its diode is its tendency to conduct electric current in only one direction. When the cathode is negatively charged relative to the anode at a voltage greater than a certain minimum called forward break over, then the current flows through the diode. If the cathode is positive with respect to the anode, at the same voltage as the anode, or is negative by an amount less then the forward break over the voltage, then the diode does not conduct current.

And to make the current into pulse format we use High frequency switching circuit. These pulse format will make battery not to become too heat due to the continuous current. The technique used by the high frequency circuit is the pulse charging technique. This is Trickle method in boost charging system.

A high end high Frequency charging will be employed to charge the battery without loading the turbine and photo-voltaic cell. This method reduces the charging time. For example if cell phones are charged using this way, then the cell phones will not get heated up. The switching circuit consists of the 555 timer and a MOSFET. The 555 timer works as a 
stable multi vibrator which produces pulses of required frequency.

Then the pulse format current will stored in the Battery Energy Storage System (BESS).

It is the current and typical means of smoothening tidal or solar power generation fluctuations. Such BESS based hybrid power systems require a suitable control strategy that can provide flexible energy management solution that can improve the power quality of renewable - energy hybrid power generation systems.

\section{EMBEDDED SYSTEM}

Two signals from the Hybrid power source, two signals from BESS and four signals from Transmitter will be given to the Embedded System.

To perform the various operations and conversions required to switch, control and monitor the devices a processor is needed. The processor may be microprocessor, micro controller or embedded controller. In this project an embedded controller has been preferred because of its industrial advantages in power electronics like built in ADC, RAM, ROM, USART, DAC. This leads to lesser space occupation by the circuit and also the speed of embedded controller s are more compared to the processor. The embedded controller selected for this project is PIC16F877A due to its various features. The Figure 3. Shows the functions of PIC. The PIC is mainly used for detecting and monitoring the living things in a particular area. Using this we can easily identify whether the boat is coming towards the Floating Station or not.

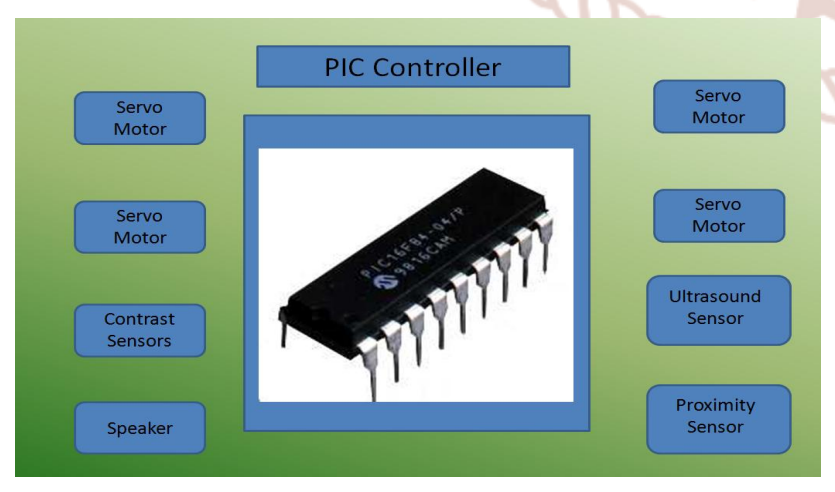

Fig 3. PIC16F877A

On providing the analog signals the embedded system will be converted to digital then digital is converted to RS-232.
In telecommunications, RS-232 is a standard for serial communication transmission of a data. It formally defines the signals connecting between a DTE (Data Terminal Equipment) such as a computer terminal, and a DCE (Data Circuit Terminating Equipment) such as modem. The RS-232 standard is commonly used in computer serial ports. As RS-232 serial port was once a standard feature of a personal computer used for connections to modems, printers, mice, data storage, and uninterrupted power. The Fig 4. Shows the pin diagram of RS-232 pin

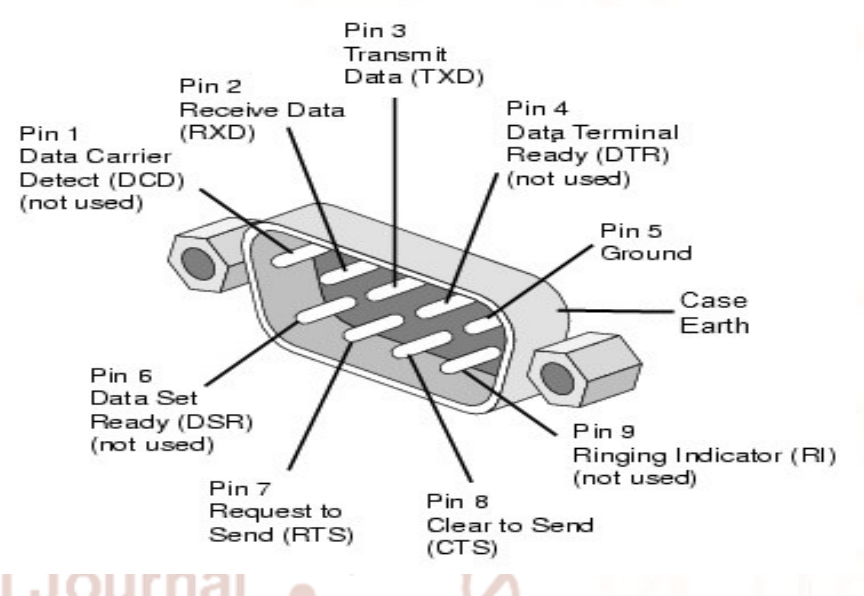

Fig 4. Pin Diagram of RS-232

The RS-232 will be then converted into USB and the message is transferred to the Personal Computer of Floating Station.

\section{TRANSMITTER AND RECEIVER}

In our proposed system we had used Unique Identification Code(UIC) for each boat which is going for fishing. It will be generated randomly like SIM card for mobile numbers. Once the fisherman returned to the seashore they will return back this code and this code will be automatically cancelled. Again the new code will generated for another boat.

Wireless frequency is given for each and every boat. It consists of four division of codes.

The first code is hidden code, Second code is used to communicate if any problem arises to him, Third code is for indicating any problem in boat, Fourth code is to intimate any other issues in boat. This information will be transmitted to receiver at the floating station, and message is transferred to coastal guards and they will help them.

The receiver at the Floating Station will receives the emergency message and it is send back to the Coastal Guards via IOT. 


\section{ALGORITHM}

In order to find out amount of energy absorbed from solar and tidal. Here we makes use of Betz law to find out the amount of received from the tides.

According to Betz law from the available tidal pressure only $65 \%$ of pressure will be converted to power(feasible electrical voltage). When A1,A2 are analog channel for solar and tidal energy and $\mathrm{I}$ is the current, then the total power is given by

$$
\begin{aligned}
& \text { Power }=\text { A1 } . \text { I }+ \text { A2 . I } \\
& \text { BESS }=\text { A1 } . \text { I }+ \text { A2 . I }
\end{aligned}
$$

RSSI is a measurement of the power present in a received radio signal. Higher the RSSI number, the stronger the signal

To calculate the distance between boat and floating Station we makes use of RSSI and humidity. If calculated value is low then the boat is far away, If the value is high then the boat is so closer.

\section{RSSI + Humidity $=$ distance}

\section{RESULTS}

The Fig 5.1 shows the details which are obtained from the Floating System.

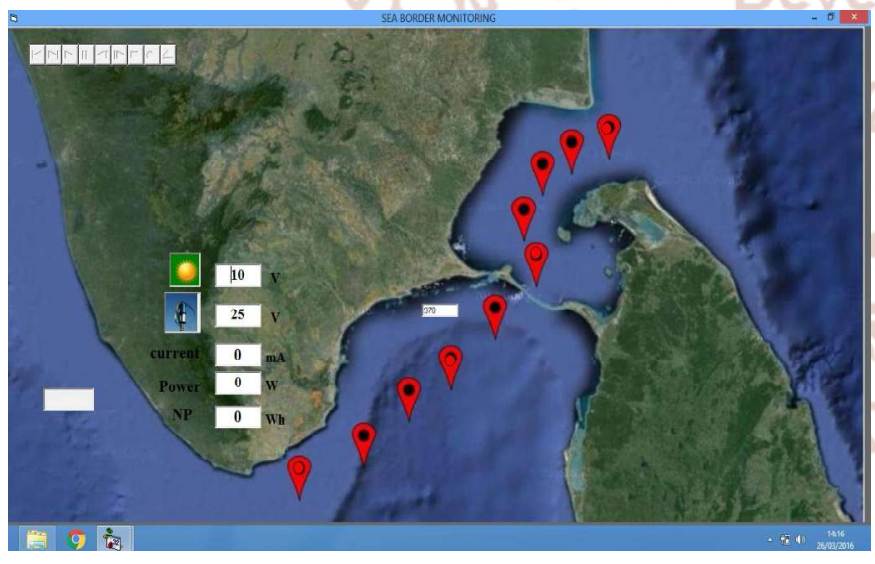

Fig 5.1. Getting details from embedded System

The Fig 5.2. Shows that boat moves beyond the Country maritime boundary. Once the boat nears our boundary it is indicated by the danger symbol and this message will be transmitted to the Coastal guard using IOT

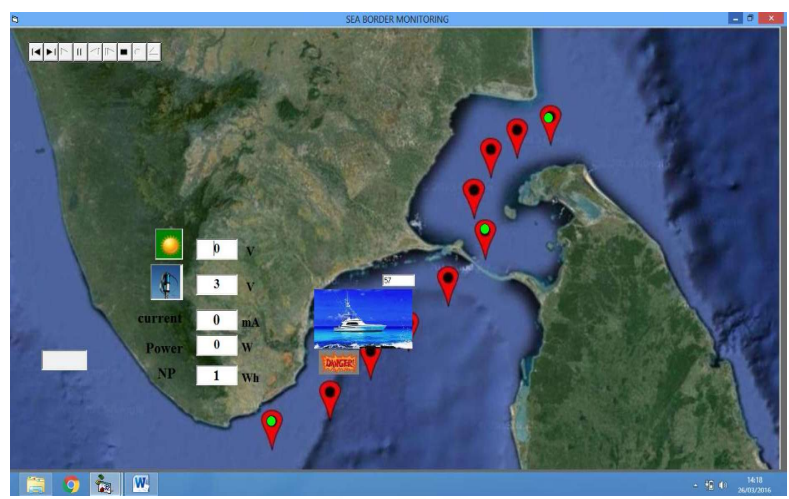

Fig 5.2. Showing that boat moves beyond Boundary

\section{CONCLUSION}

In the conventional, the fishermen have to keep watch the maritime border, which cannot be easily separated as land region. If they crossed certain limit on the sea, they have to pay penalty or get arrested by the naval guards of the neighbor country. The project generates alarm if they cross the border by mistake. with the simple circuitry and the use of Received Signal Strength Indicator(RSSI) makes the project a low cost product, which can be purchased even by a poor fisherman. This project is best suited for places where the fishermen continuously monitor the boundary limit. This system will help us to reduce the conflicts between the countries. It requires minimum human interference for communication. It is very quick and reliable. Thus our system will save the lives of fishermen and provide good relationship with the neighboring countries.

\section{REFERENCES}

1. D ArunVijay, E Yuvaraj "Design of Border Alert System for Fisherman Using GPS" ,International Journal of Students research in technology and management, Volume 2, Issue 2, March-April 2014.

2. K. Sampath Kumar ,R. Thangavel, U. TamilSelvan," Standalone Maritime Boundary Detection System using Floating Station", International Journal of Innovative Research in Science, Engineering and Technology, Vol 5, Issue 3, March 2016.

3. Nishigantha, Shirsat, Swathi, Nalawade, Monica "Study of Maritime Boundary Identification and Fisherman Patrol System", International Journal 
of Innovative Research in Science and Engineering, Voulme 2 Issue 3, March 2016

4. Kartick Eshwaran E, Mahesh S, "Design of Maritime Boundary Identifiaction System and fisherman Patrol System",International Journal of Advances in Electrical and Computer Science. Volume 1, Issue 2,December 2014,

5. M Sivamaganesh, M Ramya, V Gowtham, T Bharathi, G Jeevitha ,'Implementation of Maritime Border Alert System ", International Journal of innovative Research in Electrical,Electronics,Instrumenstration and Control Engineering, Volume 2, Issue 5,March 2014

6. B Kamalakannan, K Naresh, $>$ P Sakthivel,'Protecting fisherman's by detecting and warning them while crossing seaborder using GPS and RFID technologies", Volume 3,Issue 3 march 2015.

7. R Gomathi Bhavani, Frendrich Samuel,"GPS based system for detection and control of maritime boundary intruding boats ", International Midwest Symposium on Circuits and Systems (MWSCAS), October 16-19 2016.

8. C Pranit Jeba, Samuel, R Seethalakshmi " RF Based fishing Vessel Survillence System: An Integrated Approach", Volume 5,Issue 2, AprilMay 2013.

9. C Sheeba thangapushpam," Intelligent boundary alert system using GPS", IOSR Journal of Computer Engineering(IOSR-JCE),Volume 3,Issue 2, March 2015.

10. K Aruli, J Asha, S Mohamed Nizar, M Malathi,"A Review on GPS Tracking and Border Alert System for Fishermen", Volume 2, Issue 5,November 2015. 